\title{
Fatal complication, rescue therapy; covered stent for coronary artery perforation
}

\author{
Abdulmelik Yıldız ${ }^{1}$, Ahmet Karakurt ${ }^{2}$, Atila Bitigen ${ }^{3^{*}}$, Bayram Bağırtan ${ }^{4}$ \\ ${ }^{1}$ Private Medikalpark Hospital, Istanbul, Turkey \\ ${ }^{2}$ Department of Cardiology, Faculty of Medicine, Kafkas University, Kars, Turkey \\ ${ }^{3}$ Medikal Park, Faculty of Medicine, Kemerburgaz University, Istanbul, Turkey; "Corresponding Author: bitigen@yahoo.com \\ ${ }^{4}$ Private Avrupa Safak Hospital, Istanbul, Turkey
}

Received 9 May 2013; revised 10 June 2013; accepted 29 July 2013

Copyright (C) 2013 Abdulmelik Y1ldz et al. This is an open access article distributed under the Creative Commons Attribution License, which permits unrestricted use, distribution, and reproduction in any medium, provided the original work is properly cited.

\section{ABSTRACT}

Introduction: Although coronary perforation is a rare complication observed during intervenetional procedures, it has a considerably high mortality rate. The prevelance of coronary perforation has been reported to be $0.20 \%-0.6 \%$. Its sudden development, the patient's agitation and development of rapid collapse render intervention difficult. Materials and Method: The presence of perfusion balloon and covered stent in clinics is life-saving. In the present study, we retrospectively reviewed 17 cases with coronary artery perforation that were treated between 2009 and 2012. Of these patients, $10(58.8 \%)$ were men and $7(41.2 \%)$ were women; the median age was $62.8 \pm 8.3$ years. The coronary artery perforation resulted from guide wire in

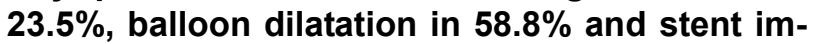
plantation in $17.6 \%$. All the lesions were either type B or C lesions. Results: The extensiveness of perforation was Ellis grade I in $23.5 \%$, grade II in $47.1 \%$ and grade III in $29.4 \%$ of the cases. In the treatment of the perforation, polytetrafluoroethylene-covered stent graft was implemented in $9(52.9 \%)$ patients, whilst conventional and emergency surgical therapy was performed in $8(47.1 \%)$ patients. Grade I perforations occurred due to the guide wire and were managed with conventional therapy $(p<0.05)$. Grade II and III perforations resulted from balloon and stent. The majority of these patients were inserted Graft Stent (stent graft in $\mathbf{5 2 . 9 \%}$ and conventional therapy in $23.5 \%$ of the cases $(p<0.05)$. Although all the stent grafts were successfully implanted, the complete control of bleeding was achieved only in $77.7 \%$ of the patients. Mortality was not ob- served in grade I perforation, whilst all cases resulted in mortality had grade III perforation. Conclusion: These data indicate that there is a need for further advanced technology in the coronary artery perforation despite of currently available therapeutic options.

Keywords: Percutaneous Coronary Artery Intervention; Coronary Artery Perforation; Covered Stent

\section{INTRODUCTION}

Coronary artery perforation is an emergency situation which is encountered rarely. Its incidence was reported to be $0.2 \%-0.6 \%[1,2]$. The diagnosis and classification of coronary perforation have been shown in the previous studies $[3,4]$. In our country, this situation was reported only as case reports in the medical literature, but there was no prospective study about this issue [5]. The interventions performed for type $\mathrm{B}$ and $\mathrm{C}$ lesions defined in $\mathrm{AHA} / \mathrm{ACC}$, and athero ablation procedures that are increasingly practiced have increased the frequency of the occurrence of perforation [6,7]. Its acute onset and rapid progression to collapse and tamponade make interventions difficult $[8,9]$. It has been demonstrated that the type of the guide wire used, the balloon/vascular diameter ratio and oversize stent are the factors for the de- velopment of perforation $[3,10]$. It is life-saving that the cardiologist performing the invasive procedure is competent and aware of this complication, avoids this complication and has accurate knowledge about how should act when this complication occurs [11]. The choice of large balloon, and high inflation pressure may result in perforation $[12,13]$. The coronary ruptures which have formed due to invasive procedure interventions are 
treated according to rupture types - the first groups are those treated by graft stent and the other group is those that are treated conservatively. The aim of this study is to compare these two groups - namely those ruptures treated by graft stent and those that are treated conservatively.

\section{MATERIALS AND METHOD}

In this study, 7452 patients who underwent percutaneous coronary artery interventions in the period between 2009 and 2012 were retrospectively reviewed by two experienced cardiologist for coronary artery perforations. The cineangiograms (Axiom Artis, Simens, Germany) of 17 patients with perforations were evaluated. Clinical and demographic features of the patients, the vessels in which the procedure was performed, the type of lesion, the cause of perforation and the extensiveness of perforation were recorded. The patients were divided into two groups depending on the treatment modalities implemented after perforation. The group I consisted of the cases treated with polytetrafluoroethylene (PTFE)covered stent and the group II consisted of the patients treated with conventional approaches. The AHA/ACC classification was used to determine the type of lesion. Ellis grading system was used for the largeness of perforation. Ellis grade I was defined as the formation of extra-luminal crater; grade II as pericardial or myocardial blush without contrast jetting; a grade III was defined as perforations larger than $1 \mathrm{~mm}$ in diameter. This study protocol was approved by ethics committee of hospital and all patients' relatives gave their informed consent.

\section{STATISTICAL ANALYSIS}

For statistical analyses, SPSS version 17 pack program
(SPSS Inc., Chicago, Illinois, USA) was used. In the analyses of differences, chi-square analysis for appropriate chi-square distribution parameters, and Mann Whitney $U$ test were used. Any $p$ value $<0.05$ was set to be significant.

\section{RESULTS}

Of the patients, $10(58.8 \%)$ were men and $7(41.2 \%)$ were women; the median age of the patients was $62.8 \pm$ 8.3 years. Of the vessels in which the intervention was done, $11(64.7 \%)$ were LAD and $6(35.3 \%)$ were CX. All coronary artery lesions were type $\mathrm{B}$ and $\mathrm{C}$ lesions according to AHA/ACC classification. There was no statistically significant difference between two groups with regard to demographic features and perforated vessel. Given the causes of perforation, it was found that guide wire-related perforations were grade I lesions and the perforations due to the balloon and stent were grade II or grade III perforations. This situation was found to be significant $(\mathrm{p}<0.05)$ (Table 1).

Among the patients in the group I (covered stent group), the causes of perforation were balloon (66.7\%) and stent $(33.3 \%)$. In the group II (conventional group) patients, the causes of perforation were found to be guide wire $(50 \%)$ and balloon $(50 \%)$. The differences between the groups were found to be significant $(p<0.05)$. By the largeness of perforation, the frequencies of grade I, II, and III perforations were found to be $0 \%, 55.6 \%$, and $44.4 \%$, respectively, in the group I and $50 \%, 37.5 \%$, and $12.5 \%$, respectively, in the group II. The differences were statistically significant (Table 2).

The grade I perforation was not observed in the group I patients, whilst the grade III perforation was found in

Table 1. The relation between Ellis grade and perforation causes.

\begin{tabular}{|c|c|c|c|c|c|c|c|}
\hline \multirow{2}{*}{ Parameters } & \multicolumn{2}{|c|}{ Group I (n = 9) } & \multicolumn{2}{|c|}{ Group II (n = 8) } & \multicolumn{2}{|c|}{ Total $(\mathbf{n}=17)$} & \multirow{2}{*}{$\mathbf{p}$} \\
\hline & $\mathbf{n}$ & $\%$ & $\mathbf{n}$ & $\%$ & n & $\%$ & \\
\hline \multicolumn{8}{|l|}{ Grade I } \\
\hline Guide wire & 0 & 00.0 & 4 & 100.0 & 4 & 100.0 & \multirow{3}{*}{$<0.05$} \\
\hline Balloon & 0 & 00.0 & 0 & 00.0 & 0 & 00.0 & \\
\hline Stent & 0 & 00.0 & 0 & 00.0 & 0 & 00.0 & \\
\hline \multicolumn{8}{|l|}{ Grade II } \\
\hline Guide wire & 0 & 00.0 & 0 & 00.0 & 0 & 00.0 & \multirow{3}{*}{$<0.05$} \\
\hline Balloon & 3 & 60.0 & 3 & 100.0 & 6 & 75.0 & \\
\hline Stent & 2 & 40.0 & 0 & 00.0 & 2 & 25.0 & \\
\hline \multicolumn{8}{|l|}{ Grade III } \\
\hline Guide wire & 0 & 00.0 & 0 & 00.0 & 0 & 00.0 & \multirow{3}{*}{$<0.05$} \\
\hline Balloon & 3 & 75.0 & 1 & 100.0 & 4 & 80.0 & \\
\hline Stent & 1 & 25.0 & 0 & 00.0 & 1 & 20.0 & \\
\hline
\end{tabular}

Group I: Covered Stent; Group II: Conventional Treatment; Grade: Ellis Grade. 
Table 2. Angiographic, demographic and clinic characteristics of the patients.

\begin{tabular}{|c|c|c|c|c|c|c|c|}
\hline \multirow{2}{*}{ Parameters } & \multicolumn{2}{|c|}{ Group I (n = 9) } & \multicolumn{2}{|c|}{ Group II (n = 8) } & \multicolumn{2}{|c|}{ Total $(n=17)$} & \multirow{2}{*}{$\mathbf{p}^{*}$} \\
\hline & $\mathbf{n}$ & $\%$ & $\mathbf{n}$ & $\%$ & $\mathbf{n}$ & $\%$ & \\
\hline \multicolumn{8}{|l|}{ Gender } \\
\hline Male & 5 & 55.6 & 5 & 62.5 & 10 & 58.8 & \multirow[t]{2}{*}{0.815} \\
\hline Female & 4 & 44.4 & 3 & 37.5 & 7 & 41.2 & \\
\hline \multicolumn{8}{|l|}{ Risk Factor } \\
\hline $\mathrm{DM}$ & 4 & 44.4 & 4 & 50.0 & 8 & 47.0 & \multirow{3}{*}{0.139} \\
\hline HT & 3 & 33.3 & 1 & 12.5 & 4 & 23.5 & \\
\hline HL & 2 & 22.2 & 1 & 12.5 & 3 & 17.7 & \\
\hline \multicolumn{8}{|l|}{ Lesioned Vessel } \\
\hline LAD & 7 & 77.8 & 4 & 50.0 & 11 & 64.7 & \multirow[t]{2}{*}{0.370} \\
\hline $\mathrm{CX}$ & 2 & 22.2 & 4 & 50.0 & 6 & 35.3 & \\
\hline \multicolumn{8}{|l|}{ Lesion Type } \\
\hline Type B & 6 & 66.7 & 3 & 37.5 & 9 & 52.9 & \multirow[t]{2}{*}{0.321} \\
\hline Type C & 3 & 33.3 & 5 & 62.5 & 8 & 47.1 & \\
\hline \multicolumn{8}{|c|}{ Mechanism of Rupture } \\
\hline Guide wire & 0 & 0 & 4 & 50.0 & 4 & 23.5 & \multirow{3}{*}{$<0.05$} \\
\hline Balloon & 6 & 66.7 & 4 & 50.0 & 10 & 58.8 & \\
\hline Stent & 3 & 33.3 & 0 & 0 & 3 & 17.6 & \\
\hline \multicolumn{8}{|c|}{ Perforation Severity } \\
\hline Grade I & 0 & 0 & 4 & 50.0 & 4 & 23.5 & \multirow{3}{*}{$0.036^{*}$} \\
\hline Grade II & 5 & 55.6 & 3 & 37.5 & 8 & 47.1 & \\
\hline Grade III & 4 & 44.4 & 1 & 12.5 & 5 & 29.4 & \\
\hline
\end{tabular}

${ }^{*}$ Test result is significant at 0.05 level (\%95 C.I.) ${ }^{*}$ Mann Whitney-U Test; Group I: Covered Stent; Group II: Conventional Treatment, Grade: Ellis Grade. Lesion type: AHA/ACC classification for coronary lesion, DM: Diabetes Mellutus; HT: Hypertension; HL: Hyperlypidemia.

only one patient in the group II. When all patients were evaluated, $58.8 \%$ of the patients were men, $47 \%$ were diabetics. It was observed that the perforation occurred in LAD (64.7\%), type B lesions (52.9\%) and $47.1 \%$ of perforations were grade II perforations. In the group I, although all stent grafts were successfully implanted, complete control of bleeding was achieved in $77.7 \%$ of the patients. In the group II, medical treatment and follow up, prolonged balloon inflation, pericardiocentesis, and/or emergency surgical treatment were performed. The inhospital mortality rate was calculated as $11.7 \%$ for whole patients.

\section{Treatment Options}

Covered stent (Group I): The polytetrafluoroethylene-covered JoStent Graftmaster VR Stent (Abbott Vascular, Redwood city, CA, USA) was inserted in 9 (52.9\%) of 17 patients because of Ellis grade II and III perforations. The patients were successfully implanted JoStent Graftmaster (sizes $3 \times 16 \mathrm{~mm}$ or $3.5 \times 19 \mathrm{~mm}$ ) stents with a pressure of 16 - 18 atmospheres. One stent sufficed in all cases. After the procedure, thrombolysis in myocardial infarction 3 (TIMI 3) flow and full control of bleeding $(77.7 \%)$ were ensured. Postoperative mortality occurred in two patients with grade III perforation, in whom stent graft couldn't suffice to control bleeding and therefore emergency surgery was performed.

Conventional treatment (Group II): Conventional treatment seems to be the treatment of choice for grade I and II perforations. In our study, 8 cases were treated in conventional manner. Conventional treatment involves medical treatment, balloon tamponade, pericardiocentesis and surgical treatment.

Medical treatment: Once the diagnosis of perforation was made, it was given intravenously $1 \mathrm{mg}$ of protamine for every 100 units of heparin. If hypotension developed, physiological saline and vasopressor infusion (dopamine, 10 - $15 \mathrm{microgram} / \mathrm{kg} / \mathrm{min}$ ) were given; the patients who developed vagal reaction, 0.5 - $1 \mathrm{mg}$ of atropine was administered. 
Balloon tamponade: In grade I and II perforations, compression was made inflating the balloon of stent used with low-pressure proximally to or within the perforation area. A perfusion balloon was used in case there was a need for prolonged balloon inflation.

Pericardiocentesis and surgical treatment: The cases who developed tamponade were first performed pericardiocentesis. Surgical repair was done if the symptoms of tamponade did not resolve with pericardiocentesis, infusions of fluid and vasopressors, and consequently cardiogenic shock emerged. Surgical intervention resulted in mortality in 2 of 5 patients. The rate of surgical mortality was $2 / 5(40 \%)$. Of the patients having grade I perforations, one case was performed surgical intervention since there were signs of tamponade 7 hours after pci, other one patient was performed pericardiocentesis alone. Mortality was not observed among the cases with grade I perforations.

\section{DISCUSSION}

In our study in the ellis type 2 - 3 rupture caused by invasive procedures, greft stent was implanted with a success rate of $50 \%$ and the rupture was taken under control $77.7 \%$. In cases in which greft stent could not be implanted and in cases where the stent could not treat the rupture, the mortality rate among the patients who were operated has reached $40 \%$.

Since the percutaneous coronary angioplasty was first performed by Andreass Gruetzing in humans in 1977, it has begun to perform interventions for more complicated coronary lesions in parallel to the technological advances. The significance of coronary artery perforation is resulted from the sudden emergence of its clinical picture and high mortality rate. Therefore, it is important to previously recognize the cases at risk. The clinical risk factors involve advanced age, cardiac failure, low creatinine clearance, myocardial infarction without ST elevation. Angiographically type $\mathrm{B}$ and $\mathrm{C}$ lesions according to AHA/ACC, the uses of atherectomy devices, cutting balloon, hydrophilic guide wire, and oversize balloon and stent (balloon/artery size: $1.19+0.17$ ) and post dilatation with high pressure emerge the risk of perforation $[3,7$, 13].

In coronary artery perforation, the most important factor designating mortality is the extensiveness of perforation. In grade III perforations, sudden onset tachycardia, chest pain, agitation, hypotension, increased jugular venous pressure, rapid development of tamponade may occur. In these patients, promptly inserted PTFEcovered stent prevents the development of sudden tamponade and cardiogenic shock [10,14]. Ellis et al. reported an incidence of tamponade of $63 \%$ and a mortality rate of $19 \%$ in coronary artery perforations [3]. In our study, in grade II and III perforations, the incidence of tamponade was $41.1 \%$ and the mortality rate was $11.7 \%$. Both patients died had grade III perforations. The incidences of grade I, II and III perforations were reported to be $16.7 \%, 54.2 \%$ and $29.1 \%$, respectively [15]. In our study, we found the incidences of grade I, II and III perforations as $23.5 \%, 47.1 \%$ and $29.4 \%$, respectively. Grade I perforations occur in association with guide wire, have a slowly progressing clinical course and good prognoses. They may be neglected since there were no extravasations, and may lead to the picture of tamponade even after 24 hours.

Despite the conventional treatment options are practicable in grade I and II perforations; these modalities are unsatisfactory for grade III perforations. The stent grafts are life-saving for these cases. Alexandra J. et al. reported full control of bleeding in $92.8 \%$ of the cases with stent grafts [15]. Briguori C. et al. demonstrated that tamponade, emergency cardiac surgery and total major adverse cardiac events were significantly infrequent among the patients treated with covered stent [16]. The rates of tamponade, emergency bypass surgery and death were $8 \%, 18 \%$, and $2 \%$, respectively, among patients implanted covered stent; whereas, these rates were reported as $82 \%, 88 \%$ and $35 \%$, respectively, among cases given conventional therapy. In that study, full control of bleeding was achieved in $91 \%$ of the cases [16]. In our study, we ensured TIMI 3 flow and full control of bleeding in $77.7 \%$ of the patients with stent graft. Currently, the most widely used stent grafts are Symbiot Stent (Boston Scientific), Josent Graft Stent (Abbott) and Nuvasc Graft Stent (Cardiovasc) [17]. In our study, PTFE- covered JoStent Graft master stents were used.

Rigid nature of stent grafts, demands of extra backup and high pressure seem to be their disadvantages. As a result of that, their success rates are low in distal, tortuous and calcify lesions. Moreover, it was reported that with these stents, sub acute stent thrombosis and restenosis were more frequent in comparison with other stents [8].

Coil embolization seems to be an option in distal lesions, small vessels, chronic total occlusions, and in cases with perforation not allowing surgery [18].

If extravasations persist despite of interventional processes, surgical operation is needed to legate the perforated vessel, to implant bypass graft for distal perfusion, and to drain tamponade. Among the patients undergoing surgery, the rates of mortality and morbidity are rising depending on the time elapsed. In our study, the rate of surgical mortality was $2 / 5(40 \%)$.

\section{CONCLUSION}

In conclusion, coronary artery perforations most often occur in LAD, type B lesions, and as a consequence of balloon dilatations with high pressure. In perforations, 
clinical course and mortality are associated with extensiveness of perforation and therapeutic modalities implemented. Among the patients undergoing surgery, the rates of mortality seem to be very high, probably due to the time elapsed. Therefore, the patient, as far as possible, should be treated in the catheter laboratory implementing stent graft and/or balloon tamponade procedures. The data indicate that there is a need for a more proper technology despite of the current treatment options.

\section{REFERENCES}

[1] Chou, G.L., Pinnow, E., Flood, R., Bonnet, Y., Tebeica, M., Waksman, R., et al. (2000) Incidence, management and outcome of coronary artery perforation during percutaneous coronary intervention. American Journal of Cardiology, 86, 680-682.

doi:10.1016/S0002-9149(00)01053-5

[2] Kimbiris, D., Iskandrian, A.S., Goel, I., Bemis, C.E., Gehl, L., Owens, J., et al. (1982) Transluminal coronary angioplasty complicated by coronary artery perforation. Catheterization and Cardiovascular Diagnosis, 8, 481487. doi:10.1002/ccd.1810080507

[3] Ellis, S.G., Ajluni, S., Arnold, A.Z., Popma, J.J., Bittl, J.A., Eigler, N.L., et al. (1994) Increased coronary perforation in the new device era. Incidence, classification, management, and outcome. Circulation, 90, 27252730. doi:10.1161/01.CIR.90.6.2725

[4] Topaz, O., Cowley, M.J. and Vetrovec, G.W. (1992) Coronary artery perforation during angioplasty: Angiographic detection and demonstration of complete healing. Catheterization and Cardiovascular Diagnosis, 27, 284-288. doi:10.1002/ccd.1810270408

[5] Yorgun, H., Canpolat, U., Aytemir, K. and Oto, A. (2012) Emergency polytetrafluoroethylene-covered stent implantation to treat right coronary artery perforation during percutaneous coronary intervention. Cardiology Journal, 19, 639-642.

[6] Ryan, T.J., Faxon, D.P., Gunnar, R.M., Kennedy, J.W., King 3rd, S.B., Loop, F.D., et al. (1988) Guidelines for PTCA. A report of American College of Cardiology/American Heart Association task force of assessment of diagnostic and therapeutic cardiovasculer procedures (subcommitee of percutaneous transluminal coronary angioplasty). Circulation, 78, 486-502. doi:10.1161/01.CIR.78.2.486

[7] Al-Mukhaini, M., Panduranga, P., Sulaiman, K., Riyami, A.A., Deeb, M. and Riyami, M.B. (2011) Coronary perforation and covered stents: An update and review. Heart View, 12, 63-70.

[8] Gunning, M.G., Williams, I.L., Jewitt, D.E., Shah, A.M., Wainwright, R.J. and Thomas, M.R. (2002) Coronary artery perforation during percutaneous intervention: İnci- dence and outcome. Heart, 88, 495-498. doi:10.1136/heart.88.5.495

[9] Von Sohsten, R., Kopistansky, C., Cohen, M. and Kussmaul, W.G. (2000) Cardiac tamponade in the new device era: evaluation of 6999 consecutive percutaneous coronary interventions. American Heart Journal, 140, 279283. doi: $10.1067 / \mathrm{mhj} .2000 .107996$

[10] Joint Working Group on Coronary Angioplasty of the British Cardiac Society and British Cardiovascular Intervention Society (2000) Coronary angioplasty: Guidelines for good practice and training. Heart, 83, 224-235. doi:10.1136/heart.83.2.224

[11] Shimony, A., Zahger, D., Van Straten, M., Shalev, A., Gilutz, H., Ilia, R., et al. (2009) Incidence, risk factors, management and out-comes of coronary artery perforation during percutaneous coronary intervention. American Journal of Cardiology, 104, 1674-1677. doi:10.1016/j.amjcard.2009.07.048

[12] Stankovic, G., Orlic, D., Corvaja, N., Airoldi, F., Chieffo, A., Spanos, V., et al. (2004) Incidence, predictors, inhospital, and late outcomes of coronary artery perforations. American Journal of Cardiology, 93, 213-216. doi:10.1016/j.amjcard.2003.09.042

[13] Javaid, A., Buch, A.N., Satler, L.F., Kent, K.M., Suddath, W.O., Lindsay Jr., J., et al. (2006) Management and outcomes of coronary artery perforation during percutaneous coronary intervention. American Journal of Cardiology, 98, 911-914. doi:10.1016/j.amjcard.2006.04.032

[14] Alexandra, J.L, Yi-ming, Y., Yosef, K., Costa, R.A., Pietras, C., Tsuchiya, Y., et al. (2006) Treatment of coronary artery perforations complicating percutaneous coronary intervention with a polytetrafluoroethylene-covered stent graft. American Journal of Cardiology, 98, 370-374. doi:10.1016/j.amjcard.2006.02.041

[15] Briguori, C., Nishida, T., Anzuini, A., Di Mario, C., Grube, E., Colombo, A., et al. (2000) Emergency polytetrafluoroethylene covered stent implantation to treat coronary ruptures. Circulation, 102, 3028-3031. doi:10.1161/01.CIR.102.25.3028

[16] Romaguera, R. and Waksman, R. (2011) Covered stents for coronary perforations: Is there enough evidence? Catheterization and Cardiovascular Interventions, 78, 246253. doi:10.1002/ccd.23017

[17] Mahmud, E. and Douglas Jr., J.S. (2001) Coil embolization for successful treatment of perforation of chronically occluded proximal coronary artery. Catheterization and Cardiovascular Interventions, 53, 549-552. doi: $10.1002 / \mathrm{ccd} .1221$

[18] Shimony, A., Joseph, L., Mottillo, S. and Eisenberg, M.J. (2011) Systematic review/meta-analysis coronary artery perforation during percutaneous coronary intervention: A systematic review and meta-analysis. Canadian Journal of Cardiology, 27, 843-850. doi:10.1016/j.cjca.2011.04.014 